\title{
Merits of Creating a Revised CTE National Research Agenda for 2020
}

\author{
Jeanea M. Lambeth ${ }^{\mathrm{a}}$, Richard M. Joerger ${ }^{\mathrm{b}}$, Jack Elliot ${ }^{\mathrm{c}}$ \\ ${ }^{a}$ AgroDyne Solutions, ${ }^{b}$ Dordt College, ${ }^{c}$ Texas A \& M University
}

This article promotes the idea that clearly focused scholarly inquiry needs direction developed through a collaborative and informative process. The authors propose that the National CTE Research Agenda adopted in 2008 should be revised and updated to reflect the contemporary issues and policies of the career and technical education profession. The aim of this discussion is to propose a systematic research approach with the potential to influence policy for career and technical education. The challenge for our profession will be to create a united and informed agenda that will transform policy, promote innovation in scholarly endeavors, and foster improved outcomes for all CTE stakeholders.

Keywords: research, career and technical education, research agenda

\section{Introduction}

Research is an important aspect of the educational profession since topics for study are typically generated from ideas developed in graduate courses and from prior research of professors and researchers in academia. The idea for focused and directed inquiry in the profession is developed through intense introspection and vetting of topic areas which are contemporary and robust in the development of new directions for future study and which contribute meaningfully to the existing body of knowledge. Research and scholarship in education, especially career and technical education (CTE), has seen a shift in thinking and perspective over the past several decades. The most important influences in shaping CTE research have come from federal legislation and the philosophies about the nature of vocational education (Rojewski, 2002; Rosenfeld, 1987). Educational policies have shaped the focus for scholarship on a national level and the policies were guided by leaders within the career and technical educational service areas (i.e., agricultural education, home economics, and industrial education).

Historically, research in CTE has been developed by researchers in separate service areas for the sole use of their specific field, professional journals and publications. Through the years, many scholars have proposed research agendas and the idea of a directed pathway for knowledge development of a larger scale for the service area. These former agendas were rarely used or adopted on a national scale, which led to the evolution and development of the framework developed in 2008 (Lambeth, 2008).
Educational research and scholarship has been described by Lagemann (2000) as:

Neither singular in focus nor uniform in methods of investigation, education research grew out of various combinations of philosophy, psychology, and the social sciences, including statistics. The variety that has characterized educational scholarship from the first, combined with the field's failure to develop a strong, self-regulating professional community, has meant that the field has never developed a high degree of internal coherence. (p. ix)

These sentiments seem to encompass the resistance by many educational scholars to engage in the discussions and activities involved in the development of a directed and structured form of research for the CTE field. This makes sense when thinking about the diverse preparation and experiences that individual service areas in CTE provide, meaning the division of thought may not necessarily be driven truly by differences in opinion, just merely differences in experience. Scholarly endeavors are implicitly personal journeys for new career researchers in the quest for promotion in academic institutions. This work promotes the idea that clearly focused scholarly inquiry needs direction developed through a collaborative and informative process. The authors propose to revisit the National CTE Research Agenda adopted in 2008 (Lambeth, Elliot \& Joerger, 2008), which should be revised and updated to reflect the contemporary issues and policies of the career and technical education profession. 


\section{Conceptual Framework}

Meaningful contributions to the body of knowledge are paramount in CTE research. The process of identifying new knowledge through research "is a systematic attempt to provide answers to questions" (Tuckman, 1999, p. 4). Many scholars propose ideologies in the development of scholarship; however, Creswell (2015) promotes the idea that research is important because (a) it adds to our knowledge base, (b) improves practice, and (c) informs policy debate.

There is a pronounced need for the positive influence of coordinated national level CTE research and development activities. The foundational philosophies, purposes, functions, and unique educational contributions related to CTE are largely unknown, undervalued, and not widely accepted. Although CTE is viewed by CTE professionals as an educational strategy for teaching reading, mathematics, science, and communications, the research necessary to support this view is sorely lacking. As a result, educators and policymakers do not place a high value on CTE as a core component of secondary and post-secondary education.

Figure 1 illustrates the diversity of CTE audiences served by CTE researchers, graduate students, and faculty; administrators; and policy and program leaders. In addition to serving their faculty and administrative roles, working with a variety of audiences and collaborators who have a breadth of needs, CTE researchers participate in producing CTE research, developing research leaders, shepherding CTE leaders, and using their research and expertise to influence policy and practice. Likewise, policy leaders influence and assist in developing and implementing programs. Aware of the needs of the CTE audiences, policy leaders regularly interact with $\mathrm{CTE}$ researchers to address emerging and critical research needs. CTE research activities and research plans are enhanced by relationships and partnerships with engaged leaders from government, business/industry, and organizations such as Association for Career and Technical Education (ACTE), CTE Advance, and Association for Career and Technical Education Research (ACTER). The authors and their colleagues agree that a revised CTE national research agenda is core to informing a strategic and coordinated plan of action to address the critical issues facing audiences who benefit from CTE research.

We propose that if key organizations, namely ACTE, ACTER, and Advance CTE, and the CTE disciplines are in unison with a national research agenda, then business/industry and the government will be more inclined to also accept and support CTE initiatives.

\section{The National CTE Research Agenda}

In 2008, Lambeth created a national CTE research agenda utilizing a Delphi process and developed a research agenda framework model (Figure 2), which was

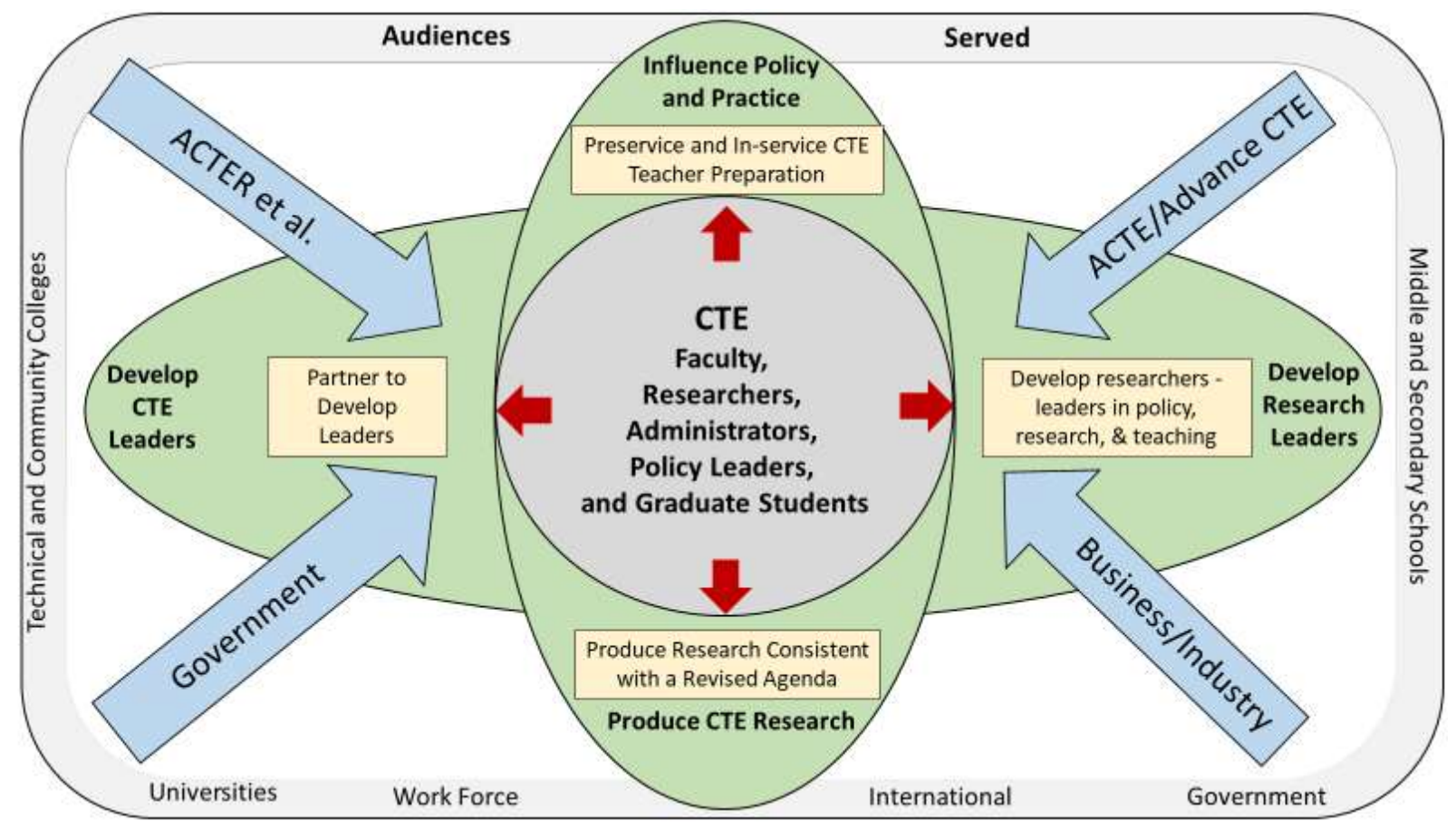

Figure 1. CTE Researcher's Functions, Partnerships, and Actions Framework (Joerger, Elliot, Kotamraju, and Retallick (2017). Reprinted with permission. 
adopted by ACTE and ACTER. Since adoption 10 years ago, this model was integrated into the professional development conference for ACTER for about seven years, and a national research clearinghouse webpage was created by ACTE and accessible through the national website for about three years. The status of the use of this research agenda model as a guide for research in CTE is a topic ripe for discussion in the current climate of change in the profession.

Demographics shifts due to an aging workforce as well as changes in immigration policy, economics, technological advancements, social and cultural changes, world conflicts, educational advancements, and geopolitical partnerships are contributing to the need for additional research within CTE and workforce issues. Likewise, refocused environmental initiatives, new and updated educational policies, new student needs, and changing worker and consumer preferences over the past 20 years warrant revisiting and restructuring a programmatic CTE research framework.

The credibility of the 2008 National CTE Research Agenda model was the result of the input of CTE experts and stakeholders from across the United States using a Delphi research process (Lambeth, 2008). This group consisted of 25 states and the District of Columbia, which represented 57 professional organizations, affiliations, institutions and businesses with direct ties to CTE. The Delphi process was conducted with three Delphi Rounds and two model validation rounds. The model included five research problem areas, 15 research objectives, and 53 research activities (not displayed).

In $2007,96 \%$ of participants in the final validation round for the study agreed to accept the final depiction of the model for the CTE National Research Agenda (Figure 2). Lambeth (2008) noted that "this model should be viewed by stakeholders as a descriptive model and not a prescriptive model" and should be used to develop a more detailed and descriptive national research agenda since the model depicts immediate needs (p. 146). She also recommended "one or more national organizations in CTE should create an educational process for monitoring and keeping state and national leaders updated in emerging CTE research" (p. 148).

Lambeth also recommended that "discussion be encouraged to begin to define or redefine the philosophy of CTE," further stating that a "unified philosophy will provide a foundation from which to build both collaboration and research focus" (p. 148). Further, she proposed:

CTE at the state and national levels should develop a unified system for influencing public policy in education and CTE based on research. These

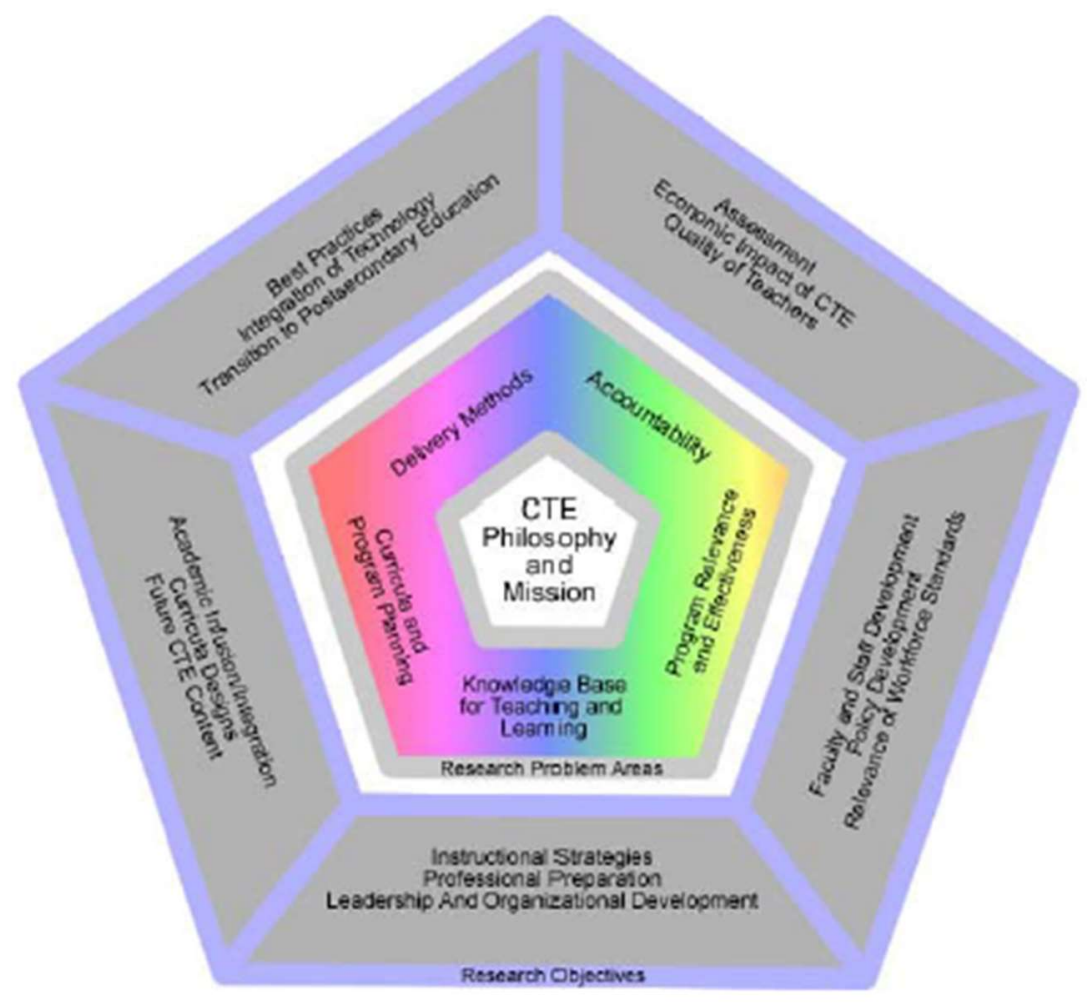

Figure 2. 2008 National Career and Technical Education Research Agenda Framework Model (Lambeth, 2008, p. 125). Reprinted with permission. 
systems should collaborate and operate cooperatively, forming partnerships, networks, and alliances with other noteworthy organizations, faculties, and research institutes. This should be an immediate action rather than a long-range goal. (Lambeth, 2008, p. 147)

Respondents from the initial 2008 study made suggestions including "Let's be sure to explore the 'core' of the model...what ought to be CTE's philosophy? Based on what set of values?" and "We can't funnel our research and ignore what's going on in the world around us" (Lambeth, 2008, p. 126). This initial research agenda resulted in a focus for professional development and scholarly activities in ACTER. The study also maintained the idea that a sustained effort for rigorous research in CTE should be made by scholars in collaboration with national and international associations and organizations who have a vested interest in the outcomes from CTE research. Lambeth (2008) argued:

CTE at the state and national levels move toward a better unified system for influencing public policy in education and CTE based on research. These systems should collaborate and operate cooperatively, forming partnerships, networks, and alliances with other noteworthy organizations, faculties, and research institutes. (p. 149)

Since the development of the current CTE research agenda framework has been published, there have been studies to develop individual service area research agendas based upon the National CTE Research Agenda Framework Model, i.e.: agricultural education, which supports the notion that a focused scholarly agenda is crucial to the profession of CTE.

\section{Background and a Historical Perspective}

Many scholars have proposed the idea of focused and informative research for education on a broad scale. At this point in our discussion it is important to look back into how research in CTE has been fostered and organized by a national organization or a CTE service area. It is hoped that through reflection, readers will recognize the importance of our argument to revisit the current National CTE Research Agenda in a unified fashion. This discussion will focus on proposed research agendas from individual CTE service areas.

Agricultural Education. Initially Buriak and Shinn (1993) developed the Agricultural Education Research Agenda as a model for research. It focused on four priority areas and 52 research objectives using a Delphi process. In 2011, Doerfert developed a national research agenda for agricultural education by utilizing a tworound survey and a feedback session at the national conference. This agenda model included six research priorities proposed to guide the profession research efforts for five years. This agenda was followed up by Roberts, Harder and Brashears (2016) with the American
Association for Agricultural Education: National Research Agenda 2016-2020. The agricultural education service area utilizes the structured research agenda approach for research within agricultural education to build the knowledge base in a purposeful and meaningful manner. The profession supports work within the parameters of the national research agenda through professional development, graduate research, and individual scholarly contributions.

Industrial Education and Technology Education. An industrial education research agenda was developed by Pucel (1995) by reviewing the top-tier journals in the field of industrial and vocational education. However, this agenda did not provide a path for future directions for research and implications for the profession. To follow up this effort, Martin and Ritz (2012) and Ritz and Martin (2012) expanded the development of a research agenda for a segment of industrial education through their studies in technology education for the United States and on the international level. They determined through their Delphi process a list with explanatory descriptions of specific topics to guide scholars and researchers for inquiry in technology education. These authors deemed that a research agenda was important for the development of research and knowledge focused on the service area of industrial education and technology education.

Family and Consumer Sciences (formerly Home Economics). Way (2001) noted in the 20th century special issue of Family and Consumer Sciences Research Journal that authors summarized research in the field of family and consumer sciences in specific areas such as food, nutrition and health, family studies, textiles and clothing, consumer science, family studies, and housing, equipment and design. She further discussed the achievements made in the profession and suggested the need for further research since the specialty area of family and consumer sciences "has grown in sophistication and both theoretically and methodologically" (p. 115). Nichols et al. (2009) argued that a growth in the body of knowledge for family and consumer science was necessary based upon the advancement and changes in the social, technological and economic conditions in the United States. These suggestions were developed from the author's point of view, and not based upon information gathered from a national study.

National Centers. Expanded resources enabled leaders and researchers of the National Research and Dissemination Centers for Career and Technical Education to revisit the needs within the profession. Researchers collaborated in a joint effort of the National Dissemination Center for Career and Technical Education (NDCCTE) and the National Research Center for Career and Technical Education (NRCCTE) to conduct a needs assessment study in 2000. Lewis (2001) reported the most important needs facing the field of CTE. A follow-up study was conducted by the same 
centers in 2003; this study explored the themes from previous studies and specifically guided the researchers toward the development of a research, dissemination and professional development agenda for CTE (Pearson \& Champlin, 2003). The National Assessment of Career and Technical Education (NACTE) also proposed a research agenda for CTE based upon the Carl Perkins CTE Act of 2006 (Perkins IV) (United States Department of Education, 2007). However, neither of these developed frameworks were accepted or used by ACTE or ACTER as a framework for planning professional development and scholarly endeavors.

Professional Organizations. Noting the ongoing interest in greater direction for the profession, Rojewski (2002) proposed a research framework and conceptual model for CTE research. It was based on current CTE research and the current state of education reform at the time and was intended to provide projections for the economy, work-family-community demands, and CTE more broadly. Aware of the merits of each of the earlier works, as well as the need for a more comprehensive framework, Lambeth (2008) proposed another research agenda for CTE that could inform the ACTE and ACTER research efforts. Lambeth (2008) broadened the research framework development effort by including an informative logic model which was intended as a guide for the development of new scholarship and inquiry on the problem areas, research objectives, and research activities gleaned from her national Delphi study.

Concerns about having a functional research agenda continued beyond 2015 by other researchers. For example, Kosloski and Ritz (2016) conducted a Delphi study of researchers with doctoral degrees in CTE areas in order to determine the topics that need further research in CTE. They used the study findings to create a rank ordered list of the most pressing research needs in CTE. They listed 11 research topics within general CTE and five research topics to be completed for CTE teacher preparation.

The agendas from CTE service areas discussed above propose direction for specialized areas, in the belief that their issues, policies and research focus are separate from the whole of CTE research, when in reality all sectors of CTE are seeking knowledge and scholarly activity toward similar goals and policy. Redefining and unifying an inclusive agenda for research and future development of CTE scholarship will enable the service areas to support their needs and be a part of a larger national effort.

\section{A Call for the Revision of the National CTE Research Agenda}

Noting the important, yet limited, number of citations concerning a CTE research agenda, the objective of the current article is to further build on the literature to clarify and answer the question: "Why do we need a revised research agenda in CTE?'

Aware of the pace of change in CTE, the previous frameworks for CTE research, and the need for a current framework that incorporates the best thoughts of partners, a proposal for revisiting the 2008 National CTE Research Agenda was presented at the 2017 ACTER research conference by Joerger, Elliot, Kotamraju, and Retallick (2017). The team stressed the importance of having a current research and development framework and suggested that a research framework is paramount to the survival of ACTER in order to give direction to early career, student, and veteran researchers. Finally, they contended that a framework is foundational for securing research funding, expanding the scope of research presented at the ACTER conference, and increasing the number of research articles submitted to the ACTER journal Career and Technical Education Research.

This article seeks to justify the development of a new CTE research agenda that will frame inquiry in a contemporary and focused direction. Researchers should revisit agenda frameworks of the past as well as the efficacy of the current National CTE Research Agenda (Lambeth, Joerger, \& Elliot, 2009). Recently, Gordon, Shaw, Xing and Talib-Deen (2017) conducted a content analysis of the topics presented at the Career and Technical Education Research Professional Development Conference (CTERPDC) from 2009 to 2016. The authors used the National CTE Research Agenda (Lambeth, 2008) as the conceptual framework for their study. In addition to identifying topics that misaligned with the current CTE research agenda and framework, they found that $81 \%$ of the research topics identified in the study were likely to fit within the Lambeth (2008) model. Noting that nearly $20 \%$ of the topics did not fit suggests a possible need to revise the current research agenda. Other researchers noted misalignment in the current agenda and proposed their own research agenda to include their proposed missing links to add to the national agenda.

\section{Potential Impacts of a Revision of the National CTE Research Agenda}

The authors propose that significant implications for scholarly inquiry in CTE will result from the development of a revised national CTE research agenda. Furthermore, a regularly scheduled discipline-supported (ACTER, ACTE, and CTE Advance) research agenda update would also show the educational world that CTE research is relevant to current demands and trends. Therefore, we propose that the National CTE Research Agenda should be revisited at minimum every five years to remain relevant. In addition to refocusing the inquiry of veteran CTE researchers, an agenda may be a topical and programmatic guide for research efforts of early career researchers and graduate students. The result may be increased amounts of research along with expanded 
impact within CTE. More informed, programmatic, and rigorous inquiry focused on needs of the CTE audiences is essential for a vibrant future for CTE.

Additionally, we recommend not only revising the research agenda but systematically recognizing scholars who have conducted research aligned with that agenda. For example, arranging the revised research agenda using a structure like the contents in the Institute of Education Sciences' (2018) What Works Clearinghouse. A revised agenda can feature a structure for identifying research that follows the research agenda through a framework and research objectives. Visual cues can be used to provide readers with a road map through the larger research structure. The cues identify meaningful articles with an award or recognition that is visually recognizable to readers. For example, a researcher may be acknowledged by receiving a virtual ribbon indicating that they had conducted an accountability study on assessment. This recognition could be included in research conference programs, journal article listings, etc. The key point is to develop a structure for CTE research and scholarly activities based on the input of national leaders representing CTE service areas and national organizations. Once completed, we believe the entire CTE field can embrace the contents and structure of a national CTE research agenda. The agenda can guide the research, dissemination of research, as well as practice. In addition, noting the pace that changes are happening in our economy and technology, pertinent research can inform decision making for policy, instruction, and curriculum development in the future.

A benefit of restructuring a CTE research agenda to early career researchers is the opportunity to align scholarly activity to a larger, up-to-date CTE agenda. Our suggested change to the recognition process for scholarly activity at conferences and in professional journals may be one that can provide early career researchers with another proof of scholarly activity that is directly connected to a larger CTE agenda. Aligning research with a revised or new agenda can be a clear indicator of contributions to the professional body of knowledge, as well as clearly show the effects of recent research and data collected on a regional and national level.

Finally, the largest impact may be on decision making and policy making for career and technical education and education in the United States. Decisions based upon thoughtful, rigorous, and programmatically prioritized current research can provide a systematic direction rather than the typical "one and done" effort typical of most current CTE research. Likewise, an up-todate discipline supported research agenda can provide more depth than the personal research agendas of academicians.

A lack of quality research in key or emerging areas of CTE may be more apparent and can be filled through additional directed inquiry on topics highlighted in a revised framework. A frame of contemporary and relevant research provides policymakers and others a more complete picture, a better story, and a better springboard on which to base policy decisions. By involving many stakeholders in the process of updating the CTE Research Agenda Framework, and by acknowledging scholars who conduct related studies, the Framework will become a common "household" term in the CTE profession and will be utilized by all CTE organizations and related groups.

Lastly, as we look to creating a revised research framework, we believe it is critical the agenda combines the best methods, participants, and frameworks of the past with the ideas of existing and new partners. Proposed new partners to be consulted include administrators, policymakers, and researchers from the Association for Career and Technical Education, Advance CTE, and others (e.g., University Council for Workforce and Human Resource Education). The challenge for our profession will be to create and maintain an informed and common agenda that will guide research that transforms policy, increases scholarly endeavors, informs practice, and increase the effectiveness, productivity, and satisfaction of CTE researchers and stakeholders.

\section{References}

Buriak, P., \& Shinn, G. C. (1991). A structure for a research agenda for agricultural education: A national Delphi involving internal experts. Proceedings of the National Agricultural Education Research Meeting, Gainesville, FL, 28, 158-164.

Doerfert, D. L. (Ed.) (2011). National research agenda: American Association for Agricultural Education's research priority areas for 2011-2015. Lubbock, TX: Texas Tech University, Department of Agricultural Education and Communications.

Gordon, H. R. D., Shaw, S. A., Xing, X., \& Talib-Deen, K. (2017, November). Analysis of papers presented at CTE research and professional development conferences: 2009-2016. Poster session presented at the meeting of Association of Career and Technical Education Research, Nashville, TN.

Joerger, R., Elliot, J., Kotamraju, P., \& Retallick, M. (2017, November). CTE researcher's functions, partnerships, and actions framework. Graphic from presentation at the 2017 Association for Career and Technical Education Research Annual Meeting, Nashville, TN.

Kosloski, M. F., \& Ritz, J. M. (2016). Research needs: Career and technical education. Career and Technical Education Research, 41(2), 107-130. https://doi.org/10.5328/cter41.2.107

Lagemann, E. C. (2000). An elusive science: The troubling history of education research. Chicago, IL: The University of Chicago Press.

Lambeth, J. M. (2008). Research foci for career and technical education: Findings from a national Delphi study (Doctoral dissertation). Texas A\&M University. Retrieved from http://hdl.handle.net/ 1969.1/ETD-TAMU-2864 
Lambeth, J. M., Elliot, J., \& Joerger, R. (2008). Research report: The national career and technical education research agenda. Techniques, October, 52-55.

Lambeth, J. M., Joerger, R. M., \& Elliot, J. (2009). Implications for focusing research in career and technical education and workforce development. Career and Technical Education Research, 34(3), 137-153. https://doi.org/10.5328/CTER34.3.137

Lewis, M.V. (2001). Major needs of career and technical education in the year 2000: views from the field. Columbus, $\mathrm{OH}$ : National Dissemination Center for Career and Technical Education, The Ohio State University.

Martin, G., \& Ritz, J. (2012). Research needs for technology education: A U.S. perspective. Journal of Technology Education, 23(2), 25-43.

Nichols, S. Y., Ralston, P. A., Anderson, C., Browne, L., Schroder, G. Thomas, S. \& Wild, P. (2009). The family and consumer sciences body of knowledge and the cultural kaleidoscope: Research opportunities and challenges. Family and Consumer Sciences Research Journal, 37(3) 266283. https://doi.org/10.1177/1077727X08329561

Pearson, D., \& Champlin, B. E. (2003). More Views from the field: Need sensing activities in 2002, St. Paul, MN: National Dissemination Center for Career and Technical Education.

Pucel, D. J. (1995). The Trade and industrial education research agenda: Implications for the field. Paper presented at the American Vocational Association, Denver, CO, USA.

Ritz, J., \& Martin, G. (2012). Research needs for technology education: An international perspective. International Journal for Technology and Design Education, 23(2), 767-783. https://doi.org/10.1007/ s10798-012-9215-7

Roberts, T. G., Harder, A., \& Brashears, M. T. (Eds). (2016). American Association for Agricultural Education national research agenda: 2016-2020. Gainesville, FL: Department of Agricultural Education and Communication.

Rojewski, J. W. (2002). Preparing the workforce of tomorrow: A conceptual framework for career and technical education. Journal of Vocational Education Research, 27(1), 7-36. https://doi.org/ 10.5328/JVER27.1.7

Rosenfeld, S. A. (1987). Design papers for the national assessment of vocational education. Proceedings of the National Conference on the Condition of Vocational Education (Washington, DC, September 11-12, 1986). (ERIC documentation Reproduction Service No. ED283020). Retrieved February 25, 2018, from https://archive.org/details/ ERIC_ED283020

Tuckman, B. W. (1999). Conducting educational research $\left(5^{\text {th }}\right.$ ed. $)$. Belmont, CA: Wadsworth Group.
United States Department of Education. (2007). Proposed research agenda for the national assessment of career and technical education. Washington D.C.: Author.

Institute of Education Sciences. (2018). What Works Clearinghouse, Reviews of Individual Studies. Retrieved from https://ies.ed.gov/ncee/wwc/ ReviewedStudies/\#/OnlyStudiesWithPositiveEffect s:false,SetNumber:1

Way, W. (2001). Reflections on family and consumer sciences research at the end of the millennium: An introduction and editorial note. Family and Consumer Sciences Research Journal, 30(2), 115116. https://doi.org/10.1177/1077727X01302001 